\title{
Radiation-Induced Emesis (RIE) in Extended-Field Radiotherapy for Gynecological Malignancies: Dosimetric and Non-Dosimetric Factors
}

\author{
Yu-Ming Wang ${ }^{1,2,3}{ }^{\circledR}$, Yi-Fan Chen ${ }^{1}$, Pei-Yi Lee ${ }^{1}$, Meng-Wei Ho ${ }^{1, *}$ and Eng-Yen Huang ${ }^{1,2,3, *}$ \\ 1 Department of Radiation Oncology, Kaohsiung Chang Gung Memorial Hospital, Chang Gung University \\ College of Medicine, Kaohsiung 833, Taiwan; scorpion@cgmh.org.tw (Y.-M.W.); \\ eivancubit@cgmh.org.tw (Y.-F.C.); pylee@cgmh.org.tw (P.-Y.L.) \\ 2 School of Traditional Chinese Medicine, Chang Gung University, Kaohsiung 33302, Taiwan \\ 3 Department of Radiation Oncology, Xiamen Chang Gung Hospital, No. 123, Xiafei Rd., Haicang District, \\ Xiamen 361126, China \\ * Correspondence: mwho@cgmh.org.tw (M.-W.H.); hey1200@adm.cgmh.org.tw (E.-Y.H.)
}

check for updates

Citation: Wang, Y.-M.; Chen, Y.-F.; Lee, P.-Y.; Ho, M.-W.; Huang, E.-Y. Radiation-Induced Emesis (RIE) in Extended-Field Radiotherapy for Gynecological Malignancies: Dosimetric and Non-Dosimetric Factors. Curr. Oncol. 2021, 28 , 3602-3609. https://doi.org/ 10.3390 /curroncol28050308

Received: 5 August 2021

Accepted: 14 September 2021

Published: 17 September 2021

Publisher's Note: MDPI stays neutral with regard to jurisdictional claims in published maps and institutional affiliations.

Copyright: (C) 2021 by the authors. Licensee MDPI, Basel, Switzerland. This article is an open access article distributed under the terms and conditions of the Creative Commons Attribution (CC BY) license (https:// creativecommons.org/licenses/by/ $4.0 /)$.

\begin{abstract}
Radiation-induced emesis (RIE) is usually noted during abdominal-pelvic radiotherapy. In gynecological malignancies, it is usually noted in para-aortic but not whole-pelvic irradiation. Irradiated small bowel (SB) may be associated with RIE. The significance of SB dosimetry remains unclear. Dosimetric and non-dosimetric factors were evaluated and correlated with RIE in 45 patients with gynecological malignancies undergoing extended-field radiotherapy (EFRT) (median 45 Gy) from 2006 to 2021. Early-onset RIE (within $72 \mathrm{~h}$ after the first fraction of EFRT) was noted in 10 of 12 RIE patients. RIE was significantly associated with the SB mean dose. The RIE rates were $58.3 \%$ and $15.2 \%(p=0.007)$ in patients with a low $(<63 \%)$ and high $(\geq 63 \%)$ SB mean dose. Logistic regression revealed that the SB mean dose remained the independent factor of overall RIE ( $p=0.049)$ and early-onset RIE ( $p=0.014$ ). Therefore, constraint of the SB mean dose limited to less than $63 \%$ of the prescribed dose is suggested to decrease RIE.
\end{abstract}

Keywords: radiation; emesis; small bowel; dosimetry; extended-field radiotherapy

\section{Introduction}

Radiation-induced emesis (RIE) is a common side effect in radiotherapy for abdominal malignancies. The incidence is around 40\% [1]. Quality of life is always affected due to characteristic of early onset and the impairment of food intake [1]. The upper abdomen is a more frequent site than the pelvis for the development of RIE [2,3]. Therefore, the prevention and management of RIE can avoid treatment interruption of radiotherapy. Dosimetric study for RIE may be helpful for RIE prevention. However, there is no dosimetric study about RIE in patients with abdominal malignancies. The aim of the current study is to identify dosimetric factors of RIE in these patients.

\section{Materials and Methods}

\subsection{Patients and Radiotherapy}

From September 2006 to June 2021, 45 patients who underwent extended-field radiotherapy (EFRT) to treat the whole pelvis and para-aortic lymph node (PALN) for cervical or endometrial cancers were retrospectively reviewed. Patients who met the following conditions were eligible in this study: (i) cervical or endometrial cancer confirmed by histology; (ii) clinical FIGO stage IB2-IVa cervical cancer or pathologically stage IIIC cervical cancer or stage IIIC endometrial cancer; (iii) no prior radiotherapy; (iv) age $\geq 20$ years old and performance status of the Eastern Cooperative Oncology Group (ECOG) 0-2; (v) adequate bone marrow, renal and liver function. 
Axial CT slices were acquired every 3-5 mm with thermoplastic mask fixation, supine, and arm elevation position. Treatment planning was performed using the Pinnacle treatment planning system (Philips Radiation Oncology Systems, Fitchburg, WI) or RayStation treatment planning system (RaySearch Laboratories, Stockholm, Sweden). Organs at risk (OARs) such as the kidney, spinal cord, bladder, loops of small bowel, colon, and rectum were contoured. Contouring of the bowel was based on the following principles. The rectum was delineated first. Furthermore, the colon was contoured above the rectum to trace slice by slice from sigmoid to descending, transverse, and ascending colon. The remaining bowel loops were defined as small bowel. The constraint was kidney V $20<30 \%$ for IMRT. Two-dimensional (AP/PA) or three-dimensional conformal radiotherapy (3D-CRT) using the 4-field technique, intensity-modulated radiotherapy (IMRT), or volumetric modulated arc therapy (VMAT) was delivered. Common Terminology Criteria for Adverse Events (CTCAE) version 3 was used for vomiting during the whole period of treatment recorded by a physician (E.-Y.H.) who was interested in radiation-induced bowel complications. In patients without symptoms, we routinely evaluated weekly. While patients had significant radiation-related side effects such as cramping, diarrhea or vomiting, immediate medications were prescribed for symptoms relief. The clinical target volume (CTV) delineation includes the vagina, external iliac, internal iliac, common iliac lymph, and para-aortic nodes for patients with hysterectomy. Intact uterine and cervix were additionally included in CTV for definitive radiotherapy for cervical cancer. In general, planning target volume (PTV) was an extension of CTV plus $10 \mathrm{~mm}$ in all directions. For patients who were treated with a daily image-guided setup, the PTV extension was $5 \mathrm{~mm}$. The prescribed dose was 39.6-50.4 Gy/20-28 fractions for the whole pelvis and PALN. After EFRT, lymph node/parametrial boost and high-dose-rate brachytherapy were provided dependent on the condition of the disease. Further boost to $54 \sim 60 \mathrm{~Gy}$ to gross lymph node was delivered. The boost dose for an intact cervix was 24-27 Gy /4-6 fractions using brachytherapy. Cisplatin-based concurrent chemotherapy was provided for 39 patients. SB mean dose was presented as Gy or a percentage per fraction (\%) with standardization to a 45 Gy prescription.

\subsection{Statistics}

The receiver operating characteristic (ROC) curve was used to determine the optimal cutoff $\mathrm{SB}$ volume and mean SB dose. Spearman's correlation was used to calculate the association among BMI, SB volume and mean SB dose. An independent $t$ test was used to compare dosimetry between two groups. A chi-square test was used for comparison of incidence of vomiting between different groups. Logistic regression was performed for prediction of vomiting. The statistics were proceeded by SPSS 25 (SPSS Inc., Chicago, IL, USA).

\section{Results}

\subsection{Dosimetric Data between Patients with and without RIE}

There were 45 patients reviewed in this study. The characteristics of the patients are shown in Table 1. Grade 0, 1, and 2 vomiting were noted in $33(73.3 \%), 7(15.6 \%)$, and 5 $(11.1 \%)$ patients, respectively. The onset of vomiting usually appeared within $72 \mathrm{~h}$ after the first fraction of radiotherapy in 10 patients. Two patients experienced RIE at 16 and 18 fractions after EFRT. Therefore, we defined early-onset RIE as an episode within $72 \mathrm{~h}$.

The mean dose of SB was $28.9 \pm 1.7$ and $24.8 \pm 0.8$ Gy (Figure 1a) in patients with and without vomiting $(p=0.022)$, respectively. The corresponding SB volume was $697 \pm 43$ and $868 \pm 51 \mathrm{~mL}(p=0.062)$ (Figure 1b). The mean dose of SB was $30.4 \pm 1.6$ and $24.5 \pm 0.8 \mathrm{~Gy}$ in patients with and without early-onset RIE $(p=0.002)$, respectively. The corresponding SB volume was $680 \pm 29$ and $867 \pm 51 \mathrm{~mL}(p=0.003)$. 
Table 1. Characteristics of patients $(n=45)$.

\begin{tabular}{|c|c|}
\hline Characteristics & Mean \pm SEM or Number $(\%)$ \\
\hline Age (years) & $52.0 \pm 1.7$ \\
\hline BMI $\left(\mathrm{kg} / \mathrm{m}^{2}\right)$ & $24.5 \pm 0.5$ \\
\hline \multicolumn{2}{|l|}{ Diabetes } \\
\hline No & $40(88.9 \%)$ \\
\hline Yes & $5(11.1 \%)$ \\
\hline \multicolumn{2}{|l|}{ Hypertension } \\
\hline No & $37(82.2 \%)$ \\
\hline Yes & $8(17.8 \%)$ \\
\hline \multicolumn{2}{|l|}{ Disease } \\
\hline Cervical cancer & $37(82.2 \%)$ \\
\hline Endometrial cancer & $8(17.8 \%)$ \\
\hline \multicolumn{2}{|l|}{ Prior chemotherapy } \\
\hline No & $38(84.4 \%)$ \\
\hline Yes & $7(15.6 \%)$ \\
\hline \multicolumn{2}{|l|}{ CCRT } \\
\hline No & $6(13.3 \%)$ \\
\hline Yes & $39(86.7 \%)$ \\
\hline \multicolumn{2}{|l|}{ IMRT/VMAT } \\
\hline No & $13(28.9 \%)$ \\
\hline Yes & $32(71.1 \%)$ \\
\hline \multicolumn{2}{|l|}{ EFRT dose (Gy) } \\
\hline$\leq 40$ & $6(13.3 \%)$ \\
\hline 45 & $37(82.2 \%)$ \\
\hline $50-50.4$ & $2(4.5 \%)$ \\
\hline \multicolumn{2}{|l|}{ Small-bowel volume (mL) } \\
\hline$<720$ & $17(37.8 \%)$ \\
\hline$\geq 720$ & $28(62.2 \%)$ \\
\hline \multicolumn{2}{|l|}{ Small-bowel mean dose (Gy) (\%) } \\
\hline$<28.35(63 \%)$ & $33(73.3 \%)$ \\
\hline$\geq 28.35(63 \%)$ & $12(26.7 \%)$ \\
\hline
\end{tabular}

SEM: standard error of mean.

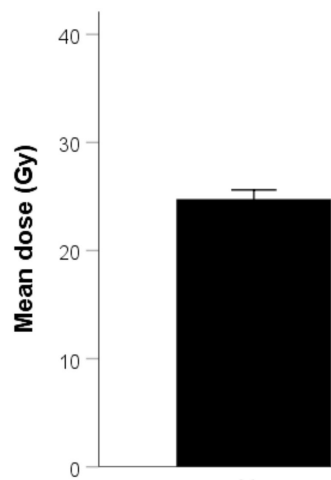

No

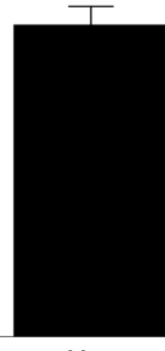

Yes

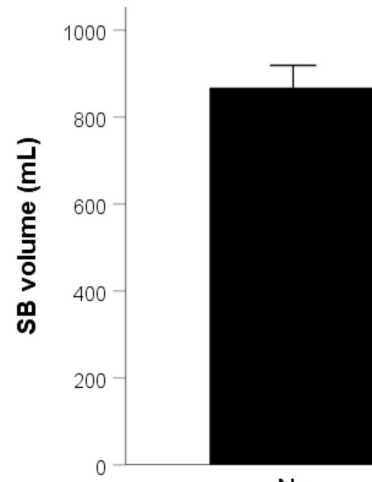

No

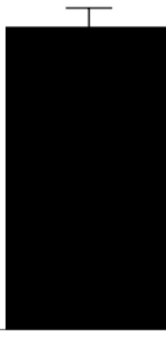

Yes

RIE

RIE

(a)

(b)

Figure 1. (a) Mean SB dose $(p=0.022)$ and (b) SB volume $(p=0.062)$ in patients without and with RIE. 


\subsection{Univariate and Multivariate Analyses of RIE}

The AUC was $0.697(p=0.045)$ (Figure 2a) for predicting vomiting and the optimal cutoff of the SB mean dose was 28.35 Gy. The AUC was $0.699(p=0.043)$ (Figure 2b) for predicting vomiting and the optimal cutoff of SB volume was $720 \mathrm{~mL}$. Table 2 shows a univariate analysis of RIE. The incidence of vomiting was $58.3 \%$ and $15.2 \%$ in patients with a high and low mean SB dose $(p=0.007)$, respectively. The corresponding rate was $52.9 \%$ and $10.7 \%(p=0.004)$ in patients with a low and high SB volume. The correlation coefficient with SV volume was $0.267(p=0.076), 0.411(p=0.005)$, and $-0.146(p=0.340)$ in age, BMI, and mean SB dose, respectively. Therefore, BMI was not included in the multivariate analysis because it was not independent with SB volume. Table 3 shows the multivariate analysis of RIE. The mean small-bowel dose $(p=0.049)$ was the independent factor of RIE.

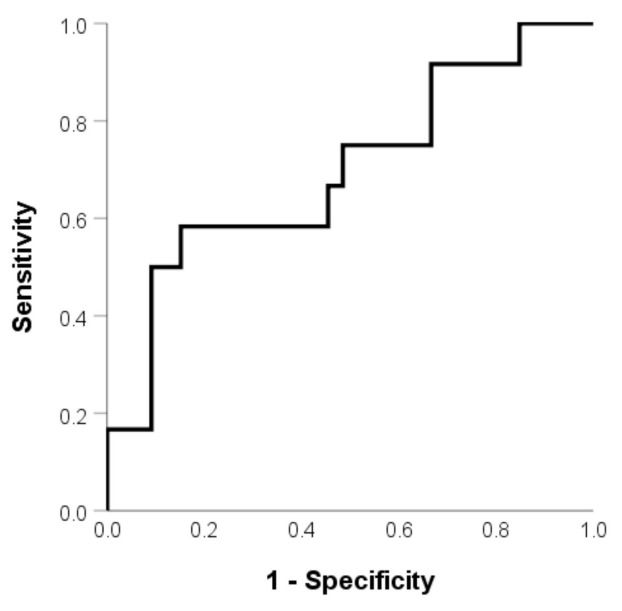

(a)

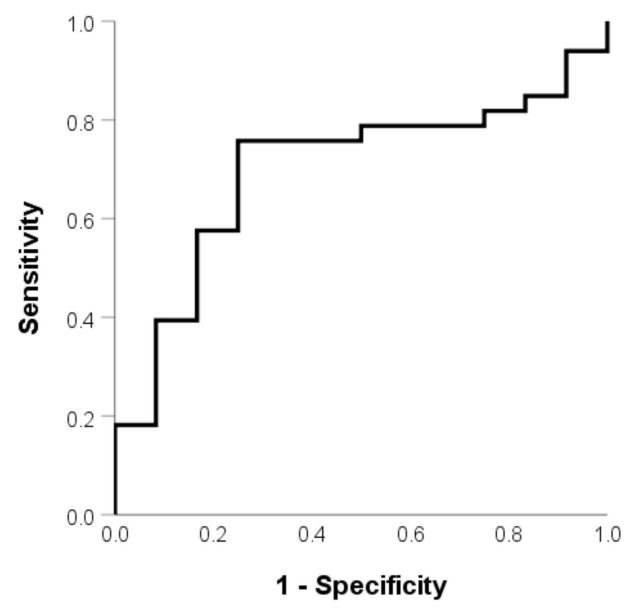

(b)

Figure 2. (a) Mean SB dose and (b) SB volume in patients without and with RIE.

Table 2. Univariate analyses of RIE.

\begin{tabular}{|c|c|c|c|}
\hline Parameters & Category & $\%$ & $p$ Value \\
\hline \multirow{2}{*}{ Age (years) } & $<56$ & $39.3 \%$ & 0.017 \\
\hline & $\geq 56$ & $5.9 \%$ & \\
\hline \multirow{2}{*}{$\mathrm{BMI}\left(\mathrm{Kg} / \mathrm{m}^{2}\right)$} & $<24$ & $34.8 \%$ & 0.208 \\
\hline & $\geq 24$ & $18.2 \%$ & \\
\hline \multirow{2}{*}{ SB volume (mL) } & $<720$ & $52.9 \%$ & 0.004 \\
\hline & $\geq 720$ & $10.7 \%$ & \\
\hline \multirow{2}{*}{ Mean SB dose (\%) } & $<63 \%$ & $15.2 \%$ & 0.007 \\
\hline & $\geq 63 \%$ & $58.3 \%$ & \\
\hline \multirow{2}{*}{ IMRT/VMAT } & No & $7.7 \%$ & 0.134 \\
\hline & Yes & $34.4 \%$ & \\
\hline \multirow{2}{*}{ PTV (mL) } & $<1635$ & $31.8 \%$ & 0.445 \\
\hline & $\geq 1635$ & $21.7 \%$ & \\
\hline \multirow{2}{*}{ Prior chemotherapy } & No & $26.3 \%$ & 1.000 \\
\hline & Yes & $28.6 \%$ & \\
\hline \multirow{2}{*}{ CCRT } & No & $33.3 \%$ & 0.650 \\
\hline & Yes & $25.6 \%$ & \\
\hline
\end{tabular}


Table 3. Multivariate analyses of RIE.

\begin{tabular}{cccc}
\hline Parameters & Category & OR $\mathbf{( 9 5} \%$ CI $)$ & $p$ Value \\
\hline \multirow{2}{*}{ SB volume $(\mathrm{mL})$} & $<720$ & reference & 0.097 \\
& $\geq 720$ & $0.197(0.029-1.343)$ & 0.049 \\
\multirow{2}{*}{ Mean SB dose $(\%)$} & $<63 \%$ & reference & \\
\hline \multirow{2}{*}{ PTV $(\mathrm{mL})$} & $\geq 63 \%$ & $6.104(1.012-36.8180)$ & 0.654 \\
& $<1635$ & reference & 0.113 \\
Age $($ years $)$ & $\geq 1635$ & $1.631(0.191-13.914)$ & \\
\hline \multirow{2}{*}{ IMRT/VMAT } & $<56$ & reference & 0.364 \\
\hline \multirow{2}{*}{ CCRT } & $\geq 56$ & $0.134(0.011-1.607)$ & 0.646 \\
& No & reference & \\
\hline
\end{tabular}

CI: confidence interval; OR: odds ratio.

Table 4 shows the multivariate analysis of early-onset RIE. The mean small-bowel dose $(p=0.014)$ remained the independent factor.

Table 4. Multivariate analyses of early-onset RIE.

\begin{tabular}{cccc}
\hline Parameters & Category & OR $(\mathbf{9 5} \% \mathbf{C I})$ & $p$ Value \\
\hline \multirow{2}{*}{ SB volume $(\mathrm{mL})$} & $<720$ & reference & 0.097 \\
& $\geq 720$ & $0.160(0.018-1.393)$ & \\
\hline \multirow{2}{*}{ Mean SB dose $(\%)$} & $<63 \%$ & reference & 0.014 \\
\hline \multirow{2}{*}{ PTV $(\mathrm{mL})$} & $\geq 63 \%$ & $13.814(1.698-112.353)$ & 0.576 \\
& $<1635$ & reference & \\
\hline \multirow{2}{*}{ Age $($ years $)$} & $\geq 1635$ & $0.527(0.056-4.982)$ & 0.118 \\
& $<56$ & reference & 0.532 \\
\hline \multirow{2}{*}{ CCRT } & No & $0.112(0.007-1.740)$ & \\
\hline
\end{tabular}

CI: confidence interval; OR: odds ratio.

\section{Discussion}

Regarding RIE, only sporadic literature is currently discussed [1]. There is no literature on its mechanism in detail or dosimetry. RIE is associated with the location of irradiation [1]. There are some dosimetric studies for RIE in head and neck cancer [4]. Dose to area postrema (AP) and dorsal vagal complex (DVC) may be associated with the development of nausea. It may be involved in the area of the brain stem that is similar to chemotherapyinduced emesis [5]. It is related to serotonin [6]. However, abdominal irradiation is bound to trigger nerve reflexes through the enteric nerve plexus to cause vomiting [5]. Whether it is vomiting caused by chemotherapy or radiotherapy, the clinical treatment medication is the serotonin receptor antagonist $[5,7]$ and the effect is quite good.

In the small intestine, serotonin is distributed in the enterochromaffin cells (ECs) in the epithelial cells, which can be said to be the neuroendocrine cells of the intestinal villi. In fact, serotonin in the SB accounts for about $90 \%$ of the whole body [8]. Animal experiments have found that cisplatin induces a vomiting pattern, and serotonin is produced in the proximal part of the small intestine more than in the distal part [5]. Once the EC is stimulated, it can secrete serotonin, which is then used as a neurotransmitter to stimulate the submucosal intrinsic primary afferent neurons and then reflex to the central nervous system [9]. From present results, low-dose radiation may trigger the vomiting reflex if a sufficient volume of SB is irradiated. It is presented as a mean SB dose. The small SB volume possibly associated with vomiting was an unexpected result in present study. No correlation between SB 
volume and mean SB dose was noted in our analysis. We hypothesize that the vagal tone may affect SB volume. There are some studies discussing the correlation between SB volume and conditions with a decreased vagal tone. Klinge et al. noted a larger SB volume in diabetes patients (mean $927 \mathrm{~mL}$ ) than health control (mean $713 \mathrm{~mL})(p=0.002)$ [10]. Brock et al. noted a decreased cardiac vagal tone (CVT) in diabetes patients [11]. Age is associated with decreased CVT [12]. In the present data, age and diabetes (data not shown) were associated with an increased SB volume. Therefore, a patient with a small SB volume may have an intense vagal tone that is predisposed to vomiting. Further prospective studies to investigate the correlation between $\mathrm{SB}$ volume and vagal tone which is measured by heart rate variability (HRV) [13-15] are encouraged.

There are some strengths and limitations in present study. To the best of our knowledge, this is the first study demonstrating the dosimetric correlation of RIE. The mean SB dose was a significant factor. We reported each grade vomiting instead of acute GI toxicity. Although chemotherapy is associated with vomiting, it was not a significant factor in the present study. Acute side effects of CCRT for cervical cancer were usually reported as acute GI toxicities. Vomiting is not separately reported or reported as "nausea or vomiting", Grade 3-4 is frequently reported instead of each grade. Yang et al. [16] revealed that $70 \%$ of patients experienced nausea during EFRT but no vomiting and no dosimetric correlation were reported. Gupta et al. reported 23.3\% Grade 3-4 vomiting that is similar to our data during the EFRT [17]. Jakubowicz et al. reported 3.3\% of Grade 3-4 nausea and vomiting in patients undergoing a whole-pelvic RT (WPRT) [18]. Uno et al. reported (100\%) nausea and vomiting in EFRT patients [19]. Although concurrent chemotherapy is a significant factor of vomiting $[20,21]$, prior chemotherapy is the other significant factor $[1,21]$. All our patients who did not receive CCRT had experience of prior chemotherapy for endometrial cancer. Therefore, no CCRT patients were chemotherapy naïve in the present study. These can explain no significant role of CCRT in RIE. Ruhlmann et al. proposed that radiation SB volume is a risk factor but no study was available [22]. However, no dosimetric correlation with RIE on small bowel was reported. Therefore, the aim of the current study, is to study this effect. We can set strict constraints of IMRT/VMAT to reduce RIE. In the present patients' group, the larger upper part of SB irradiated may be a more important factor. Marnitz et al. compared dosimetry among different techniques for WPRT or EFRT and suggested proton beam therapy to reduce complications including SB [23]. In addition, MRI-guided radiotherapy is a possible option to reduce the dose to OARs [24,25]. It may be helpful for reduction in RIE. Early-onset RIE is worth paying attention to because quality of life is always involved. The median onset time of RIE is 3 days after RT starting [1]. In whole body irradiation, prolong emesis lasts 2-3 days in about $40 \%$ patients [26]. Delayed emesis as well as cisplatin is not seen with radiotherapy, and anticipatory emesis is extremely rare [26]. Therefore, we defined $72 \mathrm{~h}$ as the cutoff time of early-onset RIE. Furthermore, the 10\% incidence of emesis (ED10) is 1 Gy [26]. From our data, the mean SB dose of $28.35 \mathrm{~Gy}$ at $45 \mathrm{~Gy}$ of the prescribed dose is transformed to $1.134 \mathrm{~Gy}$ at $1.8 \mathrm{~Gy}$ each fraction. The incidence of RIE below $1.134 \mathrm{~Gy}$ was $15.2 \%$ that is compatible with ED10. The limitation of present study is a retrospective investigation. Statistical power may be influenced by a limited sample size. A further prospective study is needed to clarify why upper abdomen irradiation is a high-risk area for RIE [21,22].

\section{Conclusions}

The SB mean dose is a significant factor of RIE. Constraint of the SB mean dose limited to less than $63 \%$ of the 45 Gy prescribed dose is suggested to decrease RIE.

Author Contributions: Conceptualization, Y.-M.W., Y.-F.C., and E.-Y.H.; methodology, Y.-M.W. and M.-W.H.; software, P.-Y.L.; validation, Y.-M.W. and M.-W.H.; formal analysis, Y.-M.W., Y.-F.C. and E.-Y.H.; investigation, Y.-M.W., Y.-F.C. and E.-Y.H.; resources, E.-Y.H.; data curation, P.-Y.L. and E.Y.H.; writing—original draft preparation, Y.-M.W., M.-W.H. and E.-Y.H.; writing-review and editing, Y.-M.W., M.-W.H. and E.-Y.H.; supervision, Y.-M.W., M.-W.H. and E.-Y.H.; project administration, E.-Y.H. All authors have read and agreed to the published version of the manuscript. 
Funding: This work was partially funded by a grant of the Ministry of Science and Technology (MOST) (109-2314-B-182A-039-MY3).

Institutional Review Board Statement: The study was conducted according to the guidelines of the Declaration of Helsinki and approved by the Institutional Review Board of the Chang Gung Medical Foundation (protocol code 202101184B0 and date of approval 15 July 2021).

Informed Consent Statement: Written informed consent of the patients or their families was waived for this kind of retrospective study by the Chang Gung Medical Foundation Institutional Review Board.

Data Availability Statement: The data presented in this study are available upon request from the corresponding author. The data are not publicly available due to ethical restrictions.

Acknowledgments: The authors would like to acknowledge the Biostatistics Center, Kaohsiung Chang Gung Memorial Hospital for their assistance in statistics.

Conflicts of Interest: The authors declare no conflict of interest.

$\begin{array}{ll}\text { Abbreviations } & \\ \text { Extended-field radiotherapy } & \text { EFRT } \\ \text { Whole-pelvic radiotherapy } & \text { WPRT } \\ \text { Concurrent chemoradiotherapy } & \text { CCRT } \\ \text { Small bowel } & \text { SB } \\ \text { Cardiac vagal tone } & \text { CVT } \\ \text { Computed tomography } & \text { CT } \\ \text { Heart rate variability } & \text { HRV } \\ \text { Body mass index } & \text { BMI } \\ \text { Intensity-modulated radiotherapy } & \text { IMRT } \\ \text { Volumetric modulated arc therapy } & \text { VMAT } \\ \text { Planning target volume } & \text { PTV }\end{array}$

\section{References}

1. Maranzano, E.; De Angelis, V.; Pergolizzi, S.; Lupattelli, M.; Frata, P.; Spagnesi, S.; Frisio, M.L.; Mandoliti, G.; Malinverni, G.; Trippa, F.; et al. A prospective observational trial on emesis in radiotherapy: Analysis of 1020 patients recruited in 45 Italian radiation oncology centres. Radiother. Oncol. 2010, 94, 36-41. [CrossRef]

2. Scarantino, C.W.; Ornitz, R.D.; Hoffman, L.G.; Anderson, R.F., Jr. Radiation-induced emesis: Effects of ondansetron. Semin. Oncol. $1992,19,38-43$.

3. Roila, F.; Hesketh, P.J.; Herrstedt, J. Antiemetic Subcommitte of the Multinational Association of Supportive Care in Cancer. Prevention of chemotherapy- and radiotherapy-induced emesis: Results of the 2004 Perugia International Antiemetic Consensus Conference. Ann. Oncol. 2006, 17, 20-28. [PubMed]

4. Wang, T.J.C.; Fontenla, S.; McCann, P.; Young, R.J.; McNamara, S.; Rao, S.; Mechalakos, J.G.; Lee, N.Y. Correlation of planned dose to area postrema and dorsal vagal complex with clinical symptoms of nausea and vomiting in oropharyngeal cancer (OPC) patients treated with radiation alone using IMRT. J. Radiat. Oncol. 2013, 2, 407-412. [CrossRef]

5. Endo, T.; Minami, M.; Hirafuji, M.; Ogawa, T.; Akita, K.; Nemoto, M.; Saito, H.; Yoshioka, M.; Parvez, S.H. Neurochemistry and neuropharmacology of emesis-The role of serotonin. Toxicology 2000, 153, 189-201. [CrossRef]

6. Naylor, R.J.; Rudd, J.A. Mechanisms of chemotherapy/radioterapy-induced emesis in animal models. Oncology. 1996, 53, 8-17. [CrossRef] [PubMed]

7. Smith, H.S.; Cox, L.R.; Smith, E.J. 5-HT3 receptor antagonists for the treatment of nausea/vomiting. Ann. Palliat. Med. 2012, 1, 115-120. [PubMed]

8. Bertrand, P.P.; Bertrand, R.L. Serotonin release and uptake in the gastrointestinal tract. Auton. Neurosci. 2010, $153,47-57$. [CrossRef]

9. Gershon, M.D. Review article: Serotonin receptors and transporters-Roles in normal and abnormal gastrointestinal motility. Aliment. Pharmacol. Ther. 2004, 20, 3-14. [CrossRef]

10. Klinge, M.W.; Sutter, N.; Mark, E.B.; Haase, A.M.; Borghammer, P.; Schlageter, V.; Lund, S.; Fleischer, J.; Knudsen, K.; Drewes, A.M.; et al. Gastric emptying time and volume of the small intestine as objective markers in patients with symptoms of diabetic enteropathy. J. Neurogastroenterol. Motil. 2021, 27, 390-399. [CrossRef]

11. Brock, C.; Jessen, N.; Brock, B.; Jakobsen, P.E.; Hansen, T.K.; Rantanen, J.M.; Riahi, S.; Dimitrova, Y.K.; Dons-Jensen, A.; Aziz, Q.; et al. Cardiac vagal tone, a non-invasive measure of parasympathetic tone, is a clinically relevant tool in Type 1 diabetes mellitus. Diabet. Med. 2017, 34, 1428-1434. [CrossRef] [PubMed] 
12. Farmer, A.D.; Coen, S.J.; Kano, M.; Weltens, N.; Ly, H.G.; Botha, C.; Paine, P.A.; Oudenhove, L.V.; Aziz, Q. Normal values and reproducibility of the real-time index of vagal tone in healthy humans: A multi-center study. Ann. Gastroenterol. 2014, 27, 362-368.

13. Thompson, J.J.; Elsenbruch, S.; Harnish, M.J.; Orr, W.C. Autonomic functioning during REM sleep differentiates IBS symptom subgroups. Am. J. Gastroenterol. 2002, 97, 3147-3153. [CrossRef]

14. Liu, Q.; Wang, E.M.; Yan, X.J.; Chen, S.L. Autonomic functioning in irritable bowel syndrome measured by heart rate variability: A meta-analysis. J. Dig. Dis. 2013, 14, 638-646. [CrossRef]

15. Pellissier, S.; Dantzer, C.; Mondillon, L.; Trocme, C.; Gauchez, A.S.; Ducros, V.; Mathieu, N.; Toussaint, B.; Fournier, A.; Canini, F.; et al. Relationship between vagal tone, cortisol, TNF-alpha, epinephrine and negative affects in Crohn's disease and irritable bowel syndrome. PLoS ONE 2014, 9, e105328. [CrossRef] [PubMed]

16. Yang, B.; Liu, X.; Hu, K.; Qiu, J.; Zhang, F.; Hou, X.; Yan, J.; Meng, Q.; Wang, W.; Yu, L.; et al. Reduction of dose to duodenum with a refined delineation method of para-aortic region in patients with locally advanced cervical cancer receiving prophylactic extended-field radiotherapy. Radiat. Oncol. 2019, 14, 196. [CrossRef] [PubMed]

17. Gupta, M.; Chopra, S.; Kunder, S.; Dheera, A.; Sampathirao, D.; Engineer, R.; Ghosh, J.; Gurram, L.; Mahantshetty, U.; Gupta, S.; et al. Early toxicity and treatment outcomes of extended field-intensity modulated radiotherapy for cervical cancer patients with para-aortic nodal metastasis. Ecancermedicalscience 2019, 13, 957. [CrossRef]

18. Jakubowicz, J.; Blecharz, P.; Skotnicki, P.; Reinfuss, M.; Walasek, T.; Luczynska, E. Early toxicity and treatment outcomes of extended field-intensity modulated radiotherapy for cervical cancer patients with para-aortic nodal metastasis. Eur. J. Gynaecol. Oncol. 2014, 35, 393-399.

19. Uno, T.; Mitsuhashi, A.; Isobe, K.; Yamamoto, S.; Kawakami, H.; Ueno, N.; Usui, H.; Tate, S.; Kawata, T.; Ito, H. Concurrent daily cisplatin and extended-field radiation therapy for carcinoma of the cervix. Int. J. Gynecol. Cancer 2008, 18, 80-84. [CrossRef] [PubMed]

20. Peters, W.A., 3rd; Liu, P.Y.; Barrett, R.J., 2nd; Stock, R.J.; Monk, B.J.; Berek, J.S.; Souhami, L.; Grigsby, P.; Gordon, W., Jr.; Alberts, D.S. Concurrent chemotherapy and pelvic radiation therapy compared with pelvic radiation therapy alone as adjuvant therapy after radical surgery in high-risk early-stage cancer of the cervix. J. Clin. Oncol. 2000, 18, 1606-1613. [CrossRef]

21. McKenzie, E.; Zaki, P.; Raman, S.; Olson, R.; McFarlane, T.; DeAngelis, C.; Chan, S.; Pidduck, W.; Razvi, Y.; Bushehri, A.; et al. Radiation-induced nausea and vomiting: A comparison between MASCC/ESMO, ASCO, and NCCN antiemetic guidelines. Support. Care Cancer 2019, 27, 783-791. [CrossRef] [PubMed]

22. Ruhlmann, C.H.; Jahn, F.; Jordan, K.; Dennis, K.; Maranzano, E.; Molassiotis, A.; Roila, F.; Feyer, P. 2016 updated MASCC/ESMO consensus recommendations: Prevention of radiotherapy-induced nausea and vomiting. Support. Care Cancer 2017, 25, 309-316. [CrossRef] [PubMed]

23. Marnitz, S.; Wlodarczyk, W.; Neumann, O.; Koehler, C.; Weihrauch, M.; Budach, V.; Cozzi, L. Which technique for radiation is most beneficial for patients with locally advanced cervical cancer? Intensity modulated proton therapy versus intensity modulated photon treatment, helical tomotherapy and volumetric arc therapy for primary radiation-An intraindividual comparison. Radiat. Oncol. 2015, 10, 91. [PubMed]

24. Massaccesi, M.; Cusumano, D.; Boldrini, L.; Dinapoli, N.; Fionda, B.; Teodoli, S.; Azario, L.; Mattiucci, G.C.; Balducci, M.; Cellini, F.; et al. A new frontier of image guidance: Organs at risk avoidance with MRI-guided respiratory-gated intensity modulated radiotherapy: Technical note and report of a case. J. Appl. Clin. Med. Phys. 2019, 20, 194-198. [CrossRef] [PubMed]

25. Boldrini, L.; Piras, A.; Chiloiro, G.; Autorino, R.; Cellini, F.; Cusumano, D.; Fionda, B.; D'Aviero, A.; Campitelli, M.; Marazzi, F.; et al. Low Tesla magnetic resonance guided radiotherapy for locally advanced cervical cancer: First clinical experience. Tumori 2020, 106, 497-505. [CrossRef] [PubMed]

26. Feyer, P.C.; Stewart, A.L.; Titlbach, O.J. Aetiology and prevention of emesis induced by radiotherapy. Support. Care Cancer 1998, 6, 253-260. [CrossRef] 